\title{
Foreign direct investment trends: an analysis of the structure and dynamics in the context of globalization
}

\author{
Liubov Kibalnyk ${ }^{1, *}$, Maryna Leshchenko ${ }^{2, * *}$, Olena Feshchenko ${ }^{3, * * *}$, and Haiyu Wang $^{2, * * * *}$ \\ ${ }^{1}$ Department of Modeling of economy and business, The Bohdan Khmelnytsky National University of Cherkasy, 81 Shevchenko Ave., \\ Cherkasy, 18031, Ukraine \\ ${ }^{2}$ Department of International Economics and Business, Cherkasy State Technological University, 460 Shevchenko Ave., Cherkasy, \\ 18030, Ukraine \\ ${ }^{3}$ Department of Economics, Entrepreneurship and Management, University of Educational Management, 52-A Sichovykh Striltsiv Str., \\ Kyiv, 04053, Ukraine \\ ${ }^{4}$ Department of Marketing and Information Science, School of Economics and Management, Qingdao University of Science and \\ Technology, 99 Songling Rd., Laoshan District, Qingdao, Shandong, China
}

\begin{abstract}
The phenomenon of the international investment activity in the context of globalization is investigated in the article. Foreign direct investment is the most important basis for further analysis of the world economy. The article discusses the current trends of the foreign direct investment flows with an emphasis on their geographical location. In particular, the inflows of FDI by region and national economies are considered. The specific features of modern factors of the foreign investments' distribution by regions are determined. The study shows that some methodological approaches are useful in determining the level of national economies' interconnection of the linked processes of international capital flows. The clustering method was used for the analysis of foreign investments and the minimum spanning trees for the selected groups of countries were constructed. From the defined list of countries, one group with similar trends in the FDI movement has been distinguished. The article stipulates that countries should consider the need for their active involvement in globalization processes and contribute to the formation of a favourable investment environment within the country.
\end{abstract}

\section{Introduction}

In recent decades, an important and defining feature of forming the world economic system is economic globalization, against which there is an active search for competitive models of national economies that would meet modern challenges of combining global trends and development patterns with national interests and goals. Modern processes of globalization are directly related to the internationalization of markets for services and capital, accompanied by increasing international mobility of national resources and the interdependence of national economies. International investment is an independent and especially important area of international economic relations being characterized by not only rapid growth and significant completion of the world trade but also its contribution to the economic growth of national economies and the increase of their competitiveness. As the processes of the world economy globalization have contributed to a dramatic increase in capital mobility and the intensification of international investment, studying and modelling of the globalization effect on the flows and structure of foreign investment are extremely relevant.

\footnotetext{
*e-mail: liubovkibalnyk@ gmail.com

**e-mail: mari.leshchenko@gmail.com

***e-mail: elf-imef@ukr.net

****e-mail: haiyuwang@hsln.cn
}

Most researchers, interpreting the concept of "the world economy globalization", are based on the processes of interdependence of national economies in the world. For example, Director-General of the International Labour Office, in his report to the 85th session of the International Labour Conference (Geneva, June 1997) notes that globalization is a complex phenomenon of economy interdependence arising from the exchange of goods and services as well as capital flows [1]. At the same time, globalization as a world-class process determines the intensification of interrelations, interaction and interdependence of states [2]. The formation of the metaspace in the conditions of forming and functioning of transnational financial and other networks formed on the basis of international capital flows, should be distinguished among the main manifestations of globalization. As a result, the manifestations of globalization for specific economic entities depend on the extent to which the carriers of capital flows - international companies - have diversified their revenues and placed their own assets in different countries in order to increase exports of goods and services and to use local advantages [3]. That is to say, the flow of foreign investment becomes the foundation of forming a unified system of relations of the new configuration of the global economy.

Foreign investment processes have always been the focus of economists' researches. Indeed, FDI is key flows in 
the international economic relations and reflects the level of economic development of an individual country. Moreover, it is important whether the country acts as a host economy or the home country of the investor. J. H. Dunning's concept of foreign investment determines that investments are made outside the host country but inside the investor's company; and investor has the control over resources (assets, capital, technology, management skills and knowledge, market access and entrepreneurship) [4] The eclectic theory of J. H. Dunning [5] determines that the beginning of the process of investing abroad is usually preceded by the analysis of three main factors of entering the international capital market: the availability of valuable assets (property benefits), location benefits and internationalization priorities [6]. Other factors that also need to be carefully analyzed include the need to control subsidiaries, the availability of resources, and company's overall strategy [7]. All these factors must be considered when choosing priorities for the development of international investment activity of the company.

M. Porter complemented the research of J. H. Dunning and made a significant contribution to the development of the theory of foreign direct investment. His theory of countries' competitive advantages assumes the ability of national firms to use internal resources in such a way as to have a competitive advantage in the world market while focusing on innovation and strategic behaviour of companies [8]. In continuation, S. Hymer defines the process of foreign investment as an operation to obtain physical assets abroad, and the current control remains with the multinational company in the home country [9]. Capital proved to be the most mobile factor of production, so it was international investment that became the dominant form of economic globalization.

Investment attraction involves justification and selection of investment priorities using transparent and clear tool set for investors. The concept of investment attractiveness can be interpreted from the point of view of both investors and recipients [10]. In modern conditions, attracting investment contributes to the development of national economies, the introduction of new technologies, the renewal of worn-out fixed assets, the creation of new jobs, and therefore, is a necessity for the proper functioning and development of the state. The activities of modern companies that are carriers of foreign investment are based on the desire to combine the benefits of efficiency through the globalization of operations and the benefits of delegating authority to subsidiaries [11].

The level of national investment risk is also an important factor in attracting foreign direct investment. Based on measurement of investment risk for different countries and the extended gravity model, the influence of national investment risk on foreign direct investment is discussed. Investment risks in various countries are totally different and instable because of the complexity of international situation. The market size of the host country, bilateral investment agreements, resource endowments and tax burden levels can also significantly affect foreign direct investment.
In today's development of global economy, its main characteristic is a distinctive trend, resulting in convergence of economic development of different countries, enhancement of industrial relations, rapid growth of international trade, migration of capital, expansion of international relations in banking and insurance spheres, intertwining of financial and stock markets, etc. [12].

To analyze the dynamics and structure of international investment, as well as other macroeconomic indicators, researchers use a number of methods and techniques. One of them is cluster analysis, which is a set of models and methods of aggregating (combining) rows of data matrix. The term of "cluster analysis" was coined by R. C. Tryon in 1939. Cluster implies the accumulation (condensation) of points-objects (rows of the data matrix) in the space of variables (columns of the data matrix) [13].

The use of cluster analysis was considered by P. E. Green, R. E. Frank and P. J. Robinson, discussed problems with determining the appropriate measure of similarity and the appropriate number of clusters [14]. J. Inglis and D. Johnson [15], D. G. Morrison [16], L. A. Neidell [17], and A. Shuchman [18] also expressed concern about the use of cluster analysis. Moreover, W. D. Wells [19] expressed reservations about the use of cluster analysis unless very different, homogeneous groups could be identified [20].

Cluster analysis is a purely empirical method of classification and as such is primarily an inductive technique [21]. Though some theorists have not been favorably disposed toward the use of cluster analysis, and criticism of the ad hoc nature of clustering solutions is common, classification is an important and frequently overlooked tool of science [20].

A. Wolf [22] has suggested that classification is both the first and last method employed by science. The essence of classification is that certain things are thought of as related in a certain way. Indeed, the final outcome of other methods of study may well be a new classification. Finally, cluster analysis has been used as a general data reduction technique to develop aggregates of data which are more general and more easily managed than individual observations [20].

In [23], the author defines cluster analysis as a multidimensional statistical procedure that collects data containing information about a sample of objects and then organizes objects into relatively homogenous groups - clusters ( $Q$-clustering, or $Q$-technique, actually cluster analysis). The main purpose of cluster analysis is the distribution of many objects and features under study into homogeneous, in the appropriate sense, groups or clusters.

\section{Research methods}

In the context of our study, it should be noted that cluster analysis allows processing a large amount of information, reducing and compressing large data sets making them compact and clear. Cluster analysis is important for the set of time series that characterize economic development (e.g., investment and commodity conditions). The use of this method makes it possible to identify the periods when 
the values of the relevant indicators were quite close, as well as to determine the groups of time series, the dynamics of which is the most similar.

A cluster is a group, a class of homogeneous units of the population. The main task of cluster analysis is the formation of such groups in multidimensional space. The homogeneity of the data set is given by the rule of calculating a certain metric, which characterizes the degree of similarity of the $j$-means and $k$-means units of the data set.

Such a metric can be the distance $C_{j k}$ between them or the similarity coefficient $r_{j k}$. Similar metrics for the selected units deemed to be uniform. Choice metric is the central point of the cluster analysis, which determines the final version of the division into classes together [24].

During the use of cluster analysis, it should be emphasized that this technique is based on two assumptions. The first assumption is that the considered features of the object, in principle, allow the desired division of the pool (set) of objects into clusters. The second assumption is the correct choice of scale or units of measuring features. In general, the method of cluster analysis involves: selecting a sample of objects for clustering, determining a set of variables, by which objects will be evaluated in the sample, if necessary, normalizing the values of variables, calculating values of similarities between objects, creating groups of similar objects (clusters), interpreting the results of the analysis.

After obtaining and analyzing the results, it is possible to adjust the selected metric and clustering method to obtain the optimal result.

To determine the "similarity" of objects, it is necessary to make a vector of characteristics for each object first; as a rule, it is a set of numerical values. However, there are also algorithms that work with qualitative (so-called, categorical) characteristics. In the process of normalization, all values are reduced to some range, e.g., $[1,-1]$ or $[0,1]$. Finally, for each pair of objects, the "distance", the degree of similarity, between them is measured. There are many metrics; here are just the main ones.

Characteristically, that the choice of cluster analysis tools entirely depends on the purpose of the study and the individual preferences of a researcher, since the results of clustering can significantly differ when using different methods.

In our study, we use dendrograms and a minimum spanning tree (MST) to show results. These methods are characterized by sequential combination of initial elements and corresponding decrease in the number of clusters. They look at the matrix of similar dimensions $N \times N$ (where $N$ - the number of objects) and gradually combine the most similar objects [25].

The dendrogram shows the distances or similarities corresponding to the construction of new clusters for each step of the agglomerative hierarchical clustering algorithm on the vertical axis on the left, and the objects combined in accordance with the analysis - on the horizontal axis. Important steps are to determine the parameters of the dendrogram, its construction and interpretation of the choice and number of clusters. Based on the proximity table and the chosen aggregation strategy, the objects in the table are gradually, step by step, merged into clusters. Hierarchical agglomerative cluster analysis uses the following strategies to work with the proximity matrix: the strategies of the nearest neighbour, far neighbour, group average, centroid strategy based on the increase of the sum of squares, flexible strategy [26].

The initial actions in the procedures of hierarchical agglomerative cluster analysis are the same. First, a pair of objects with the smallest degree of distance is looked for among all the objects of the proximity matrix and combined into one group. The columns and rows of these objects are removed, and a new column and row with the listed attribute values are inserted in their place, so as not to violate the diagonal of zeros. As a result, the size of the proximity matrix is reduced by one, and the smallest value found becomes a parameter of the dendrogram, as it determines the distance between these objects, and the group itself is denoted by the number of $n+1$. At each subsequent step, there is a merger of two objects or an object and a group or two groups, for which the degree of closeness is minimal; a similar recalculation is performed; and the combined groups are denoted as $n+2, n+3, \ldots, n+(n-1)$. The procedure is completed when the dimension of the proximity matrix is $2 \times 2$ [27]

Minimum spanning tree shows the location of system elements and their optimal combinations. Graphically, the minimum scanning tree is represented as a connected graph consisting of $n$ vertices (nodes) and $n-1$ edges. The minimum scanning tree has the shortest length among all the trees, based on the sum of distances between two elements. The minimum scanning tree reflects the hidden information contained in economic time series. Pairwise correlation coefficient is used to quantify the degree of similarity of system elements:

$$
C_{i j}=\frac{\left(Y_{i} Y_{j}\right)-\left(Y_{i}\right)\left(Y_{j}\right)}{\sqrt{\left.\left(Y_{i}^{2}\right)-\left(Y_{i}\right)^{2}\right)\left(\left(Y_{j}^{2}\right)-\left(Y_{j}\right)^{2}\right)}}
$$

where $i, j$ - variable index, $Y_{i}=\ln P_{i}(t)-\ln P_{i}(t-1)$ and $P_{i}(t)$ - values of $i$ variable at time $t$. The matrix of $n \times n$ size is composed of $C_{i j}$ correlation coefficients.

It is known that the correlation coefficient can range from -1 (completely uncorrelated pair) to 1 (completely correlated pair). The matrix of correlation is a symmetric matrix with units on the main diagonal. To understand and interpret the topological structure of the studied system, a generalized metric is used; it is determined by the formula:

$$
d_{(i j)}=\sqrt{2\left(1-C_{i} j\right)}
$$

By this definition, $d(i, j)$ numerically satisfies the following axioms:

(i) $d(i, j)=0$, if and only if $i=j$, i.e., the axiom is fulfilled under the condition of full correlation;

(ii) $d(i, j)=d(j, i)$ - the second axiom is fulfilled because we have a matrix of cross-correlation coefficients and, accordingly, a matrix of distance D symmetric by definition; 
(iii) $d(i, j) \leqslant d(i, k)+d(k, j)-$ which is numerically verified - the third axiom is fulfilled [28].

MST and the associated hierarchic tree show the existence of clusters of any market assets, information about which is important from economic point of view. The obtained taxonomy allows grouping economic objects being homogeneous in terms of economic activity [29].

When interpreting the results of cluster analysis, it is worth considering that cluster analysis has some shortcomings and limitations. In particular, the composition and number of clusters depend on the selected criteria of distribution and grouping. When reducing the original data array to more compact one, certain distortions may occur, as well as individual features of individual objects may be levelled by replacing their characteristics with generalized values of cluster parameters. Besides, when classifying objects, the possibility of the absence of any cluster values in the considered set is often ignored.

\section{Results and discussions}

The globalization of the world economy has contributed to the intensification of international investment processes and influenced the formation of the structure and dynamics of foreign direct investment. The influence of the external factors on the development of national economies has been intensified; the factors include the world markets for goods, services and production factors, global competition, economic policy of the subjects of the world economic processes involving states, regional integration groups, international organizations, transnational corporations, etc. As a result, it is worth noting the similar dynamics of gross domestic product (GDP) and foreign direct investment (FDI), as the most important indicators of economic development in general, and international investment activity, in particular (figure 1).

It should be noted since the amounts of attracting FDI provide control over business and are often associated with the ownership of tangible assets, such as equipment, buildings or other real estate, they are the main flows in the international investment processes. FDI is a determining factor that affects the rate of economic growth, and, therefore, is characterized by a high level of sensitivity to changes and transformations occurring in the global economy.

The development of the international investment under the influence of global transformations should be divided into three conditinal waves, in fact, with a 7-year period of changes, except for the last continuing till nowadays.

The first wave of investment inflows (figure $1, b$ ) is a period of stable growth from 1994 to 2001, characterized by a sixfold increase in FDI (from 278.76 billion US dollars to 1569 billion US dollars in 2000) and the beginning of short-term decline to 895.37 billion US dollars in 2001 .

The second wave of investment inflows is a period of rapid growth from 2002-2003 to 2008, characterized by more than a fourthfold increase in FDI (from 737.03 billion US dollars to 3,136.1 billion) and a two-year decline to $1,447.4$ billion US dollars in 2009 .

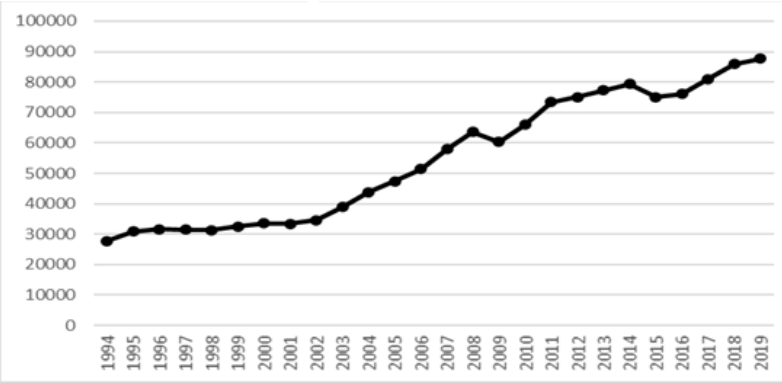

(a)

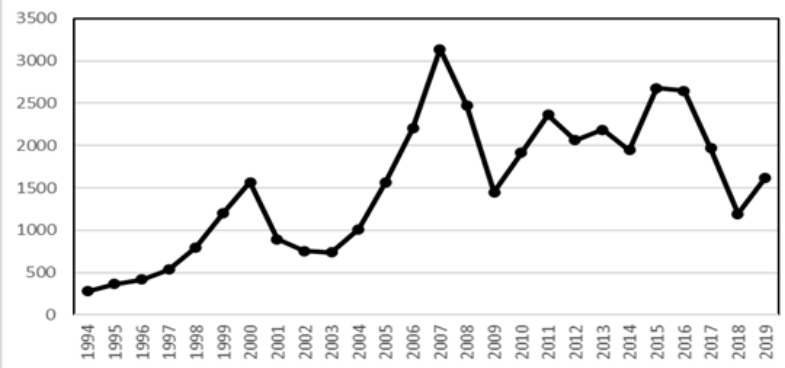

(b)

Figure 1. GDP (a) and FDI (b) dynamics in the world, 19942019 [30]

The third wave of investment inflows can be divided into 2 periods. The first period took place from 2009 to 2014 , with a gradual recovery from the previous wave and 2184.5 billion US dollars FDI in 2013. The second period is the growth of FDI during 2014-2016 and a sharp decline during 2017-2018. In 2018, FDI was much lower than in the beginning of this period and even lower than in the post-crisis period in 2009.

The analysis of the FDI dynamics showed a growing trend of FDI with wave-like movement and minimum volume in 2018. A recovery begins in 2019 and is projected to have values of 2015 in the near future.

Under the influence of global transformational shifts, the redistribution of the international investment markets occurs. The formation of regional and sectoral structure of FDI and their dynamics are influenced by a number of factors related to structural changes in the economy in the transition to a new technological level of development that, in its turn, leads to a new stage of global competition, stimulates the aggravation of geopolitical and geoeconomic contradictions (table 1) [31].

The developed countries are among the leaders in attracting FDI; however, developing countries have much higher growth rate of incoming FDI. The attracted investments in less developed and transition economies remain volatile due to their low attractiveness to investors and volatile demand for the products and resources they can offer. The FDI flows to the developed countries were over 800 billion US dollars in 2019; they exceeded the indicators of the previous year being 557 billion US dollars in 2018. The United States of America remained the most attractive investment country attracting 251 billion US dollars in FDI flows, followed by China - 140 billion US dollars and Singapore - 110 billion US dollars [32]. 
Table 1. FDI flows by region, 2017-2019 (USD billion and per cent)[31]

\begin{tabular}{|c|c|c|c|c|c|c|c|c|}
\hline Region & 1994 & 2000 & 2003 & 2007 & 2010 & 2013 & 2016 & 2019 \\
\hline \multicolumn{9}{|c|}{ US dollars at current prices in billions } \\
\hline Developed countries & 150.6 & 1119.1 & 337.9 & 1282.1 & 710.4 & 716.5 & 1265.2 & 800.2 \\
\hline Developed countries: America & 53.3 & 380.9 & 60.6 & 333.4 & 226.7 & 270.8 & 507.9 & 296.7 \\
\hline Developed countries: Asia & 1.4 & 15.3 & 9.6 & 31.3 & 5.7 & 14.1 & 31.3 & 32.8 \\
\hline Developed countries: Europe & 34.7 & 52.1 & 48.0 & 46.1 & 31.6 & 25.6 & 34.0 & 27.9 \\
\hline Developing countries & 102.4 & 231.6 & 194.9 & 522.4 & 622.0 & 656.0 & 652.0 & 684.7 \\
\hline Developing countries:Africa & 6.1 & 9.7 & 18.2 & 51.1 & 46.6 & 52.1 & 46.0 & 45.4 \\
\hline Developing countries: America & 27.7 & 79.8 & 45.6 & 116.9 & 160.7 & 185.4 & 136.6 & 164.2 \\
\hline Developing countries: Asia & 68.4 & 142.0 & 130.7 & 353.2 & 412.8 & 415.7 & 468.4 & 473.9 \\
\hline Transition economies & 1.9 & 5.9 & 17.8 & 87.2 & 63.8 & 83.9 & 66.3 & 54.9 \\
\hline \multicolumn{9}{|c|}{ percent } \\
\hline Developed countries & 59.1 & 82.5 & 61.4 & 67.8 & 50.9 & 49.2 & 63.8 & 52.0 \\
\hline Developed countries: America & 20.9 & 28.1 & 11.0 & 17.6 & 16.2 & 18.6 & 25.6 & 19.3 \\
\hline Developed countries: Asia & 0.5 & 1.1 & 1.8 & 1.7 & 0.4 & 1.0 & 1.6 & 2.1 \\
\hline Developed countries: Europe & 34.7 & 52.1 & 48.0 & 46.1 & 31.6 & 25.6 & 34.0 & 27.9 \\
\hline Developing countries & 40.2 & 17.1 & 35.4 & 27.6 & 44.6 & 45.0 & 32.9 & 44.5 \\
\hline Developing countries: Africa & 2.4 & 0.7 & 3.3 & 2.7 & 3.3 & 3.6 & 2.3 & 2.9 \\
\hline Developing countries: America & 10.9 & 5.9 & 8.3 & 6.2 & 11.5 & 12.7 & 6.9 & 10.7 \\
\hline Developing countries: Asia & 26.9 & 10.5 & 23.7 & 18.7 & 29.6 & 28.5 & 23.6 & 30.8 \\
\hline Transition economies & 0.8 & 0.4 & 3.2 & 4.6 & 4.6 & 5.8 & 3.3 & 3.6 \\
\hline
\end{tabular}

However, it is worth noting that even the recorded FDI values for these countries remained low compared to historical levels.

In particular, the FDI inflows to North America remained at 298 billion US dollars level, and total investment flows to the developed countries fell by $6 \%$ (about 643 billion US dollars being only half of the peak recorded in 2007).

Trends for the developed countries are mostly determined by the FDI dynamics in the European Union countries where the foreign investment flow fell by $15 \%$ to the indicator of about 305 billion US dollars. Although the trends for the largest players-countries were extremely diverse, FDI in the UK fell by $6 \%$ during the development of Brexit; the sale of Hong Kong and China assets caused the FDI decrease by $48 \%$ in the turbulence conditions, and the foreign investment inflows to Germany nearly tripled as multinational corporations lent to foreign affiliates during a period of slow growth.

Among developing countries, the growth engine of the group of countries remains the region of Southeast Asia where the growth of the attracted FDI was over $30 \%$ in 2019 compared to the previous year. This increase was due to the positive results of economy growth in some countries including Indonesia, Malaysia, Singapore and Vietnam especially due to the significant investment inflow to the branches of manufacturing sector. Among the countries of South Asia, the FDI distribution in the region is significantly influenced by the indicators of India where the growth of the attracted FDI was in the fields related to information technologies. In particular, the increase in the FDI inflows to Bangladesh by $50 \%$ in 2019 was due to the attraction of capital to infrastructure facilities, mainly from China. For the countries of West Asia, the average decrease of FDI was $10 \%$ except for Saudi Arabia where there was a steady increase of FDI mainly due to capital investment to chemical industry [33]. It is worth noting that most countries of West Asia continued to attract investment to the oil and gas industries.

In the region of Latin America and Caribbean countries, unstable dynamics of the FDI volumes should be noted due to the slowdown in economic development of some countries. Thus, investment flows in South America have not fluctuated dramatically as compensation for declining FDI to Brazil and Argentina and growing volumes in Chile, Peru and Colombia. Moreover, a significant increase in the FDI flows to Brazil did not ensure the introduction of new rules to facilitate sales of state-owned subsidiaries; therefore, this factor is expected to be an additional one in attracting new FDI in the coming years. In the countries with positive dynamics, growth was mainly due to additional public investment in infrastructure (Peru, Chile, Colombia), additional investment flows to mining companies (Peru, Chile), due to the efforts to improve the investment climate in national economies (Chile, Colombia). It is also worth noting a certain decrease in the volume of FDI attracted to Mexico in recent years against the background of investor's uncertainty regarding domestic policy towards the ratification of the new trade USMCA (United States-Mexico-Canada Agreement) [33]. Concerning other Central America countries, the FDI flows grew but not significantly.

Following the results of 2019, African countries slightly reduced the indicators of FDI attracted by about $2 \%$. Unstable economic development, constant tension in trade policy, political instability in several countries of the continent act as a deterrent to the FDI growth, even against the background of ratification of a new AfCFTA (African Continental Free Trade Area) [32]. As a positive result, a number of positive reforms to the rules for oil and gas 


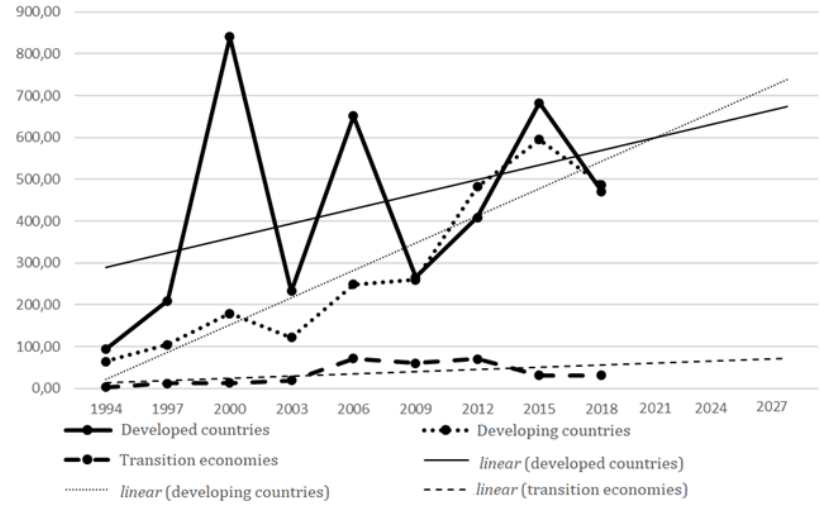

Figure 2. Wave changes in FDI according to groups of countries, 1994-2018 [30]

companies to reduce mandatory requirements to the state ownership, particularly in Nigeria, should be noted.

In countries with transition economies, the volume of FDI attracted in 2019 increased compared to 2017-2018 but were lower by $18 \%$ than the indicators of 2016 . The agreements of cross-border mergers and acquisitions involving companies from the Russian Federation, the region's largest economy mainly in the mineral resources and Internet services sectors, played a significant role in the slight increase in the indicators.

While maintaining the leadership of the developed countries, the FDI geography has significantly changed in favour of developing countries (figure 2). This can be explained by their active involvement in various international activities and a number of geopolitical and trade risks.

Based on the data of figure 2, it can be argued that since 2009, developing countries have been increasing their potential to attract FDI and may acquire the status of a leader in terms of investments attracted in the next 5-10 years.

A number of restrictions to international capital movement applied by national governments have played a significant role in changing the intensity of FDI flows. Almost all countries in the world today are members of one or more transactions on regional integration or trade agreements. These agreements focus on cross-border measures concerning services, investment and competition policy, capital movements, intellectual property rights, government procurement, standards, labour and the environment [34].

Thus, only $10 \%$ of protectionist measures adopted by countries restricted foreign investment 15 years ago, and $34 \%$ - according to the results of 2018. Moreover, most restricted measures (21\% from $31 \%$ ) in 2018 were at the expense of the developed countries. National governments banned international mergers and acquisitions being worth of about 153 billion US dollars with these instruments under the pretext of a threat to national security or for antitrust reasons.

In particular, the USA and Germany have become more cautious about foreign and especially Chinese investment due to fears that after the arrival of foreign investors to national economy, foreign investors will be able to ac- cess important technologies and assets making economic security vulnerable. This trend has become characteristic to the countries of the European Union. For example, in the spring of 2018, the European Commission adopted regulations to verify any foreign investment in the countries of the union. China, in its turn, tried to limit the outflow of capital abroad that led to a reduction of Chinese foreign investment in recent years. In addition, as a result of Donald Trump's reform, American corporation repatriated profits, as a result of which the US national economy lost its leading positions in terms of investment abroad.

This structure and dynamics of the FDI movement shows a special role of public policy of countries in shaping the investment attractiveness of their own economy. We should note that the distribution of the global FDI flows is based on the factor of investment attractiveness of countries. This is especially important in the context of globalization of the world economy and profound structural changes occurring under the influence of technological innovations, and requires all countries to mobilize their own resources and capabilities. Researches show that different methods of assessing investment attractiveness that are mainly developed for certain levels of economic system, are based on processing the indicators of attracting FDI. Ultimately, national economies with favourable investment climate determined by a set of legal, financial, political, social, and cultural factors stipulate the feasibility of investing in a particular economic system; and a change in the investment climate leads to redistribution of investment flows in the world economy and is a determining factor in the activity of investors.

In order to identify the relationships between different countries with different rates and indicators of economic development and to determine their future prospects, we use the method of cluster analysis of indicators of attracting FDI and the generalized indicator - the annual index of actual foreign direct investment (according to UNCTAD). This index estimates and classifies 140 countries by comparing FDI and GDP of each country and is a ratio of a country's share of world FDI flows to its share of the world GDP [35]. A country with higher ratios of GDP, employment and exports in the corresponding aggregate (global) indicators will receive higher share of FDI inflows. If the inflow index of an investment country is higher than 1 , it means that the country receives more foreign direct investment than could be predicted by comparing the above ratios.

To implement clustering, we chose the index of the actual inflow of foreign direct investment for 15 countries belonging to different groups of countries in terms of economic development (the USA, Brazil, UK, China, Hong Kong, Singapore, Japan, Canada, Germany, Mexico, Russia, Poland, Belarus, Ukraine, and Azerbaijan) and the volume of FDI received by these countries for the same period of time, namely for the period of 1994-2019. The investigation period was chosen considering the following features: first, all countries had to be independent; second, the correct construction of trees required databases to be large enough to analyze the obtained results accurately; third, since 1994, all selected countries began the 


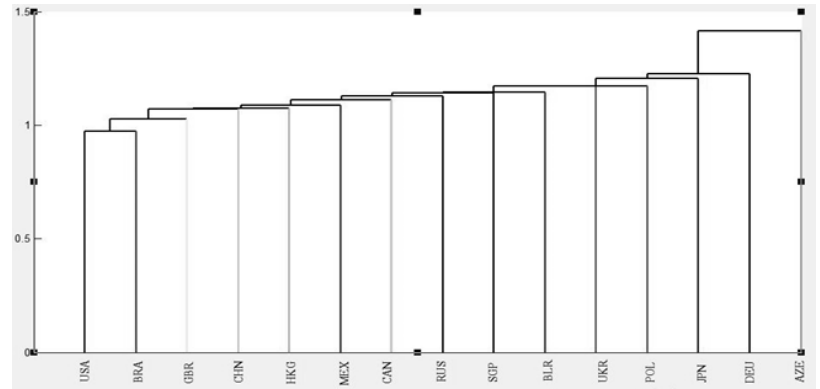

(a)

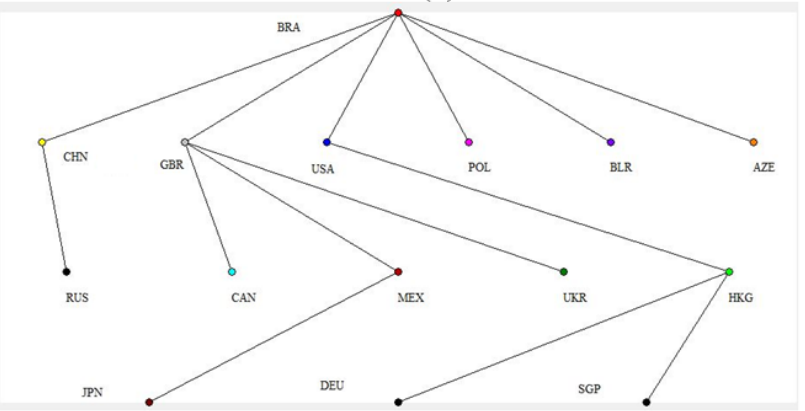

(b)

Figure 3. Dendrogram $(a)$ and minimum scanning tree $(b)$ for countries in terms of attracting FDI, 1994-2019

stable development of foreign economic relations with the rest of the world, resulting in the formation of a modern economic space.

In the process of analyzing the graph of hierarchical tree, one should understand that initially, each country is a separate cluster. When building a tree, data with similar trends are combined in separate clusters depending on the strength of the relationship between them. This analysis continues until all clusters are combined into one. Ideally, the dendrogram clusters are determined (separated) by jumps at a distance from each other. If such a distance is insignificant, the clusters are close; if the jumps in distances are significant, the objects at a great distance from each other, i.e., dissimilar clusters, begin to unite into clusters. As a result of calculations, we constructed a dendrogram $(a)$ and minimum spanning tree $(b)$ for the selected countries according to both defined indicators (figures 3, 4).

Data analysis of figure $3(a)$ makes it possible to separate one cluster, which is clearly demarcated. This cluster involves the USA and Brazil. The values of this cluster are close to 1 ; therefore, it can be concluded that their relationship is also quite insignificant. All other clusters are formed indistinctly; a consistent overlap is observed. The analysis of the relationships between other countries shows that the separated cluster is a core, which other clusters gradually join (a core and periphery that joints this core alone). The overlap of each subsequent country with the previous one means that there is no strong connection between the rest of the countries that could unite them. In addition, the analysis of distances between objects in the feature space allow us to conclude that there is a very slight difference in features for countries. The number of

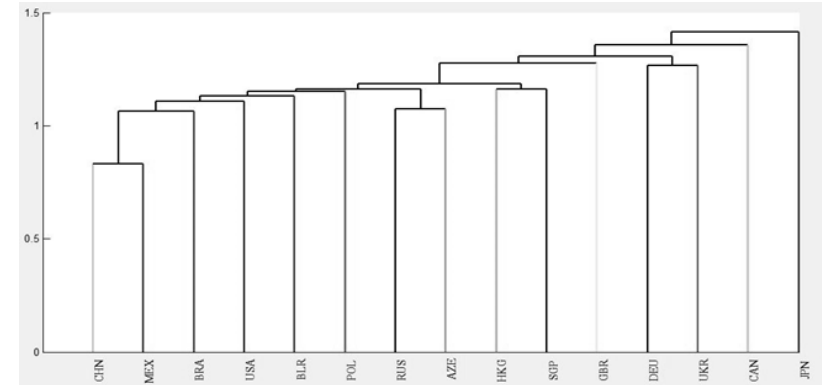

(a)

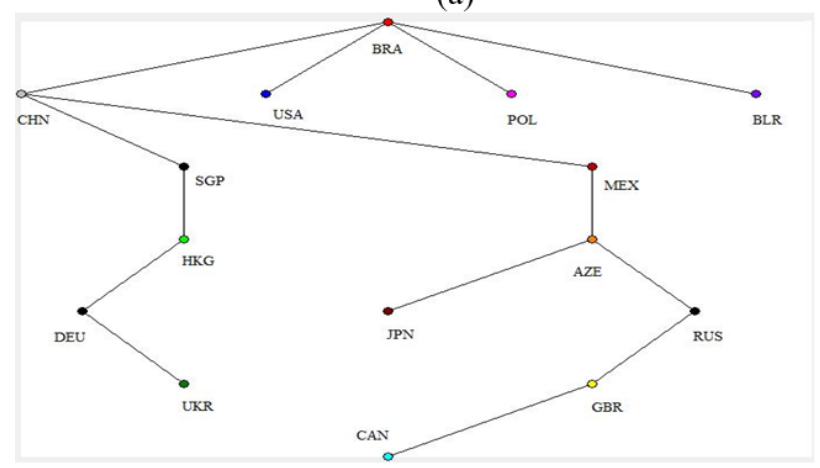

(b)

Figure 4. Dendrogram $(a)$ and minimum scanning tree $(b)$ for countries on the index of actual FDI inflow, 1994-2019

dendrogram levels is quite large that indicates that many steps need to be taken to form clusters.

The location of these countries in the same cluster can be explained by the fact that the USA and Brazil are quite close to each other compared to the rest of the countries; and the United Kingdom has strong relations with both countries through the so-called "traditions of the past", when it had direct influence on these countries, and later had stable economic relations with them. The constructed minimum scanning tree gives a visualization of the obtained results of cluster analysis on the plane. The main concentrators are Brazil, United Kingdom and Hong Kong (figure 3,b).

Dendrogram and minimum scanning tree were constructed according to the index of actual inflow of foreign direct investment in order to identify changes in relations between the studied countries (figures $4,(a, b)$ ).

Since dendrograms allow us to show the relationship between the studied objects, we can assume according to our calculations that the pattern in terms of the level of investment attractiveness is observed between the Russian Federation and Azerbaijan due to the significant influence of the Russian Federation on the economic development of Azerbaijan since its independence. In the cluster Hong Kong - Singapore, Hong Kong plays the main part; its policy influences the investment activity and development of Singapore, therefore, the changes in the indicators of investment attractiveness of the first country immediately influence the other country. It is also worth noting that most of the formed clusters are interconnected by geographical location; so, it is very important factor in the movement of FDI and the formation of the influence 
of more powerful countries on their neighbours. Among other countries, clustering with the intensity it should be due to the usual generalization of economic indicators, is not observed. The data of figure $4(b)$ shows the formation of three clusters. The first one involves Brazil, China, Poland, and Belarus; the second - Azerbaijan, Mexico, Japan, United Kingdom, Canada, and the Russian Federation. The changes in the indicators of investment attractiveness within these clusters will be similar.

\section{Conclusion}

Thus, liberalization of international capital movements, the intensification of FDI flows are important factors of the globalization of the world economy, since in the conditions of uneven distribution of capital in the world economy, open access to additional financial resources for developing countries, and gives additional opportunities for productive use of surplus capital using the advantages of local markets in the host countries, for the developed countries. At the same time, it has been proven that FDI contributes to the development of stable and long-term economic relations between countries. Indicators of the relative attractiveness of the national economy for foreign investors include absolute and relative values of the FDI flows and characterize current changes of the FDI flows in the globalization levels for a definite period of time. Quantitative indicators allow monitoring of manifestations of globalization processes, in particular, international investment activity that is important not only for research but also for business and public administration in order to make decisions in response to changes in the dynamic economic environment. According to the obtained analysis results, it can be stated that the international exchange of foreign investments is an unstable cyclical process. In particular, so far, most players in the international capital market have failed to restore pre-crisis level of investment activity. Asian and Latin American developing countries remain the most attractive countries for foreign investment in recent years. We can conclude that such trends show the long-term prospects of economic development of these regions, and geopolitical uncertainty in the world significantly affects the dynamics of the volume and structure of international investment.

The analysis of the results shows that on the basis of the index of actual inflows of foreign direct investment, it is possible to track the trends of dynamics of international investment in the world. The results of the analysis show that this country is Brazil; it is the country that has the greatest number of connections with the rest analyzed countries. This makes it possible to distinguish one group of countries from a set analyzed, which have similar trends of the FDI movement. The group involves the USA, China, Brazil, Poland, Belarus. That is to say, if there is a change in the indicator in a positive or negative direction, similar changes should occur for all countries within the cluster. However, for more accurate results, it is necessary to expand the number of countries studied. It has been determined which of the countries selected for anal- ysis with different level of development in the context of globalization has the greatest impact on the rest.

According to the FDI dynamics, the main concentrators are Brazil, United Kingdom and Hong Kong. But results of the FDI index of the actual inflow show that the main concentrators are Brazil, China and Mexico. These results confirm one of the main modern trends, a trend of economic growth of emerging markets and developing economies. The presence of Brazil and Mexico, Singapore and Hong Kong in the same cluster, according to the dendrogram, is a confirmation of this fact. The global share of developing economies in FDI inflows reached 54\% in 2018, where half of the top 10 host economies are developing ones. At the same time, developed countries, such as the United States, Britain, Germany, Canada and Japan retain economies that significantly affect the dynamics and structure of FDI.

The results of cluster analysis confirm the similarity of FDI dynamics between the countries. However, they are ambiguous in defining the interactions between home and host economies. Prospects for further research are the use of other methods of economic and mathematical modeling for comprehensive analysis and identification of patterns in the structure and dynamics of FDI.

\section{References}

[1] World Labour Report 1997-1998: Industrial Relations, Democracy and Social Stability (International Labour Organization, Geneva, 1998), ISBN 9221103315, http://web.archive.org/ web/20020414004243/http://www.ilo.org: 80/public/english/dialogue/govlab/publ/ wlr/97/index.htm

[2] A. Kolot, Globalization as a factor in the transformation of social and labor relations (2001), pp. 5567

[3] A. Filipenko, Global forms of economic development: history and modernity (Znannya, Kyiv, 2007)

[4] J.H. Dunning, Multinational Enterprises and the Global Economy (Addison Wesley, New York, 1993)

[5] J.H. Dunning, International business review 9, 163 (2000)

[6] O. Rogach, International investments: theory and practice of business of transnational corporations (Lybid, Kyiv, 2005)

[7] R.W. Griffin, M.W. Pustay, International business (Pearson, 1995)

[8] M. Porter, The Competitive Advantage of Nations (The MacMillan Press Ltd., London, 1990)

[9] S. Hymer, The American Economic Review 60, 441 (1970)

[10] H. Danylchuk, N. Chebanova, N. Reznik, Y. Vitkovskyi, Global Journal of Environmental Science and Management 5, 227 (2019)

[11] I. Sazonets, M. Varich, The essence of the basic concept of the activity of TNCs in the minds of globalization (Yugo-Vostok, Donetsk, 2011) 
[12] M. Leshchenko, Y. Vdovychenko, Scientific Journal of Polonia University 28(3), 23 (2018)

[13] R.C. Tryon, Cluster Analysis; Correlation Profile and Orthometric (Factor) Analysis for the Isolation of Unities in Mind and Personality (Edwards Brother, Inc., lithoprinters and Publishers, Ann Arbor, Michigan, 1939)

[14] P.E. Green, R.E. Frank, P.J. Robinson, Management Science 13, B387 (1967)

[15] J. Inglis, D. Johnson, Market Research Society. Journal. 38, 1 (1996), https : //doi .org/10.1177/147078539603800410

[16] D.G. Morrison, Management Science 13, B775 (1967)

[17] L.A. Neidell, Procedures and Pitfalls in Cluster Analysis, in Proceedings, Fall Conference, American Marketing Association (1970), p. 107

[18] A. Shuchman, Management Science 13, B688 (1967)

[19] W.D. Wells, Journal of Marketing Research 12, 196 (1975)

[20] G. Punj, D.W. Stewart, Journal of Marketing Research 20, 134 (1983)

[21] R.W. Gerard, Science 125, 429 (1957)

[22] A. Wolf, Essentials of Scientific Method (Macmillan Company, New York, 1926)

[23] M. Pistunov, Cluster analysis in economics (National Mining University, Dnepropetrovsk, 2008)

[24] O.V. Balueva, N.M. Chynkulyak, Efektyvna ekonomika (2013)

[25] Y. Williams, Methods of hierarchical classification. Statistical methods for computers (Nauka, Moscow,
2006)

[26] M. Malyutova, Statisticheskie metody dlya E'VM (Nauka, Moscow, 1986)

[27] N. Kunanets, Bulletin of the National University "Lviv Polytechnic" 783: Information systems and networks, 435 (2014)

[28] V. Eleyko, Fundamentals of econometrics (MARKA Ltd., Lviv, 1995)

[29] V. Derbentsev, O. Serdyuk, V. Solovyov, O. Sharapov, Synergetic and econophysical methods of research of dynamic and structural characteristics of economic systems (Brama-Ukraine, Cherkasy, 2010)

[30] The World Bank, World bank open data (2021), https://data. worldbank.org/

[31] UNCTADstat, Beyond 20/20 WDS - Table view - Foreign direct investment: Inward and outward flows and stock, annual (2021), https: //unctadstat.unctad.org/wds/TableViewer/ tableView . aspx?Report Id $=96740$

[32] UNCTAD, Investment trends monitor (2019), https://unctad.org/system/files/ official-document/diaeiainf2019d2_en. pdf

[33] UNCTAD, Investment trends monitor (2020), https://unctad.org/system/files/ official-document/diaeiainf2020d1_en. pdf

[34] M. Leshchenko, D. Palamarchyk, International Journal of Economics and Society pp. 280-283 (2015)

[35] M. Harrison, International Business \& Economics Research Journal 2, 93 (2003) 